\title{
Monitoring of allograft vasculopathy by intravascular ultrasound one month and one year after heart transplantation: A single center study
}

\author{
Helena Bedanova ${ }^{\mathrm{a}, \mathrm{b}}$, Marek Orbann ${ }^{\mathrm{a}, \mathrm{b}}$, Martin Tretina ${ }^{\mathrm{a}}$, Petr Fila ${ }^{\mathrm{a}, \mathrm{b}}$, Vladimir Horvath ${ }^{\mathrm{a}, \mathrm{b}}$, Jan Krejci ${ }^{\mathrm{b}}$, Petr Nemec ${ }^{\mathrm{a}, \mathrm{b}}$
}

\begin{abstract}
Aims. The aim of this trial was to use intravascular ultrasound (IVUS) to determine whether cardiac allograft vasculopathy (CAV) starts progressing during the first year after heart transplantation (HTx).

Methods. We retrospectively analyzed 51 patients ( 11 women) who received heart transplants in our center between January 2010 and September 2013 and underwent coronary angiography as well as IVUS examination one month and one year after HTx. Patients with proven calcification and fibrotic plates in the IVUS examination one month after HTx constituted a group with defined donor-transmitted atherosclerosis (DTA). In patients without DTA, measurements of maximal intimal thickening (MIT) were made in two predetermined locations.

Results. Eight of the 51 patients had DTA, while 43 did not. These were divided based on maximal intimal thickness (MIT) into a group with MIT $<0.5 \mathrm{~mm}$ (27) and MIT $\geq 0.5 \mathrm{~mm}$ (16). No patient with MIT < $0.5 \mathrm{~mm}$ developed allograft vasculopathy within one year after HTx. CAV developed in three patients $(P=0.045)$ out of the 16 patients with MIT $\geq 0.5$. In patients with DTA, a statistically significant deterioration in percent area stenosis (PAS) occurred in both artery sections $(P=0.01)$.

Conclusion. Our trial showed that CAV progresses during the first year after HTx significantly more frequently in patients with DTA and MIT $\geq 0.5 \mathrm{~mm}$. It is essential in these patients to implement an IVUS control examination one year after transplantation. The results can lead to a change in treatment strategy to prevent further progress of the disease.
\end{abstract}

Key words: heart transplantation, allograft vasculopathy, IVUS examination

Received: February 8, 2015; Accepted with revision: July 3, 2015; Available online: July 15, 2015 http://dx.doi.org/10.5507/bp.2015.034

${ }^{a}$ Center of Cardiovascular and Transplant Surgery, Brno, Czech Republic

'International Clinical Research Center, St. Anne's University Hospital Brno, Brno, Czech Republic

Corresponding author: Petr Nemec, e-mail: petr.nemec@cktch.cz

\section{INTRODUCTION}

The progression of cardiac allograft vasculopathy is regarded as the Achilles' heel of heart transplantations today. CAV is characterized by intimal proliferation which progresses at different periods after transplantation, resulting in a luminal narrowing in the allograft arteries and is the leading cause of morbidity and mortality in cardiac transplant recipients ${ }^{1}$.

Therefore, CAV represents a major clinical concern and the focus of research ${ }^{2,3}$. The precise molecular mechanism of vasculopathy progression is not known. Both immune and non-immune mechanisms have been implicated in its progression.

The prevalence of this disease has not dropped but is gradually increasing with the improvement in diagnostic methods. According to the ISHLT register, the CAV prevalence after five years since transplantation was $29.6 \%$ in 1995-2001, 31\% in 2001-2011 and 30.4\% in 2012 (ref. ${ }^{4}$ ).

Early diagnosis is limited by the lack of clinical symptoms for ischemia in denervated hearts. Angiography often underestimates the scope and gravity of the disease. The major limitation of coronary angiography in CAV detection is the lack of information regarding arterial wall anatomy. Vessel remodeling including vasodilatation, which occurs during CAV progression, can also remain undetected using angiography ${ }^{5,6}$.
Intravascular ultrasound (IVUS) is one of the more sensitive tools for CAV diagnosis. IVUS provides a view of the real diameter of the lumen artery as well as the appearance and thickness of intimal and arterial media, with significant potential for detection of even small changes. It can detect CAV at a time when it is still angiographically undetectable. Intimal thickening has been found to progress at the highest speed during the first year after HTx and then continues with slow but relentless progression $^{7}$. Fast-progressing CAV, defined as a thickening by $\geq 0.5 \mathrm{~mm}$ MIT in the first year after HTx, is connected to a significantly higher risk of death, myocardial infarction and progression of angiographically detectable, heavy CAV (ref. ${ }^{8}$ ).

For this reason, an IVUS examination 1 and 12 months after HTx is essential for the identification of high-risk patients. The aim of our study was to assess the relationship between MIT measured shortly after HTx and the progression of CAV during the first year after transplantation.

\section{METHODS}

We retrospectively analyzed the available data from 51 patients ( 11 women, 40 men) who underwent HTx in our center between January 2011 and September 2013, 
with routine coronary angiography and IVUS examinations one month and one year after HTx. Patients with proven calcification and fibrotic plates displayed in artery constituted a group defined as patients with donor- transmitted atherosclerosis (DTA) .In patients without DTA (ISHLT CAV0), the maximal intimal thickness (MIT) was measured $^{9}$. Based on MIT, they were divided into group A, with MIT $<0.5 \mathrm{~mm}$, and group B, with MIT $\geq 0.5 \mathrm{~mm}$. MIT was measured in two predefined places: branching of RIA (ramus interventricularis anterior)-RC (ramus circumflexus) and RIA-RD1 (ramus diagonalis). In patients with DTA, the following measurements and calculations were performed: lumen area (LA), vessel area (VA), and percent area stenosis (PAS).

\section{Immunosuppression and endomyocardial biopsy}

All patients were treated according to the immunosuppressive protocol, consisting of conventional triple combination of medication: cyclosporin A (Sandimmunn Neoral, Novartis) or tacrolimus (Prograf, Advagraf, Astellas Pharma), mycophenolate mofetil (Cellcept, Roche) and corticosteroids. All patients were given initial induction treatment with monoclonal antibody basiliximab (Simulect, Novartis). According to the protocol, endomyocardial biopsies were performed once per week in the first month after HTx, then once per month to a total of ten biopsies during the first year after transplantation. Histopathologic results were assessed using the Banff classification.

\section{IVUS methodology and measurement}

IVUS examination was performed one month (M) after HTx, followed by a control examination one year (Y) after transplantation. After administration of heparin, a $6 \mathrm{~F}$ catheter was installed in the left coronary artery using a guide wire. To prevent spasm, patients were - besides heparin - given $0.4 \mathrm{mg}$ of nitroglycerin sublingually before the IVUS catheter was introduced. The IVUS catheter (Volcano Eagle Eye Platinum type) was installed distally in the left coronary artery (ramus interventricularis anterior-RIA) on an ultra-thin guide and pulled by hand proximally from the distal part of the artery. Patients with proven calcification and fibrotic plates displayed in the artery constituted a group defined as the group with DTA present. Coronary calcification and ateromatosic plates were assessed based on the consensus of American Cardiology Society ${ }^{10}$ experts. In patients without DTA, maximal intimal thickness (MIT) was measured in two predefined places - branching of RIA-RC (ramus circumflexus) labeled as Measurement 1 and RIA-RD1 (ramus diagonalis) labeled as Measurement 2. In patients with DTA, the following measurements and calculations were performed: lumen area (LA1 and LA2), vessel area (VA1 and VA2) = lumen area + intimal area, and percent area stenosis $($ PAS1 and PAS2 $)=($ intimal area $/$ vessel area $)$ x $100 \%$.

Baseline parameters of the IVUS examination are shown in Fig. 1. Table 1 shows the basic interpretation criteria for intravascular ultrasound measurements.

\section{Statistical analysis}

Basic characteristics of recipients and donors were presented using methods of descriptive analysis. Results are given as means with standard deviation (SD), medians, lower quartile (Q1), upper quartile (Q3), minimum and maximum with continuous variables, and using absolute and relative numbers with categorical variables.

Categorical variables were compared using the chisquare test or Fisher's test. As the continuous variables did not show a normal distribution, the non-parametric Man-Whitney was applied to compare inter-group parameters.

All analyses were conducted at a level of significance of $5 \%$ (i.e., $P$-values $<0.05$ are considered statistically significant).

\section{RESULTS}

\section{Association between baseline MIT and CAV progression}

Baseline data and set breakdown are indicated in Table 2.

Angiography did not reveal coronary artery stenosis in any of the patients, either after one month, or after one year since HTx. In eight patients out of 51, IVUS showed DTA in the first month after transplantation, while 43 patients had no DTA. These were divided based on MIT into group A, with MIT $<0.5 \mathrm{~mm}$ (27 patients), and group $\mathrm{B}$, with MIT $\geq 0.5 \mathrm{~mm}$. No patient with MIT $<0.5 \mathrm{~mm}$ developed allograft vasculopathy within one year after HTx (Fig. 2). Three of the 16 patients with MIT $\geq 0.5$ developed allograft vasculopathy, which was statistically significant $(P=0.045)$. Furthermore, statistically significant MIT progression $(P=0.01)$ was found

Table 1. Basic interpretation criteria for intravascular ultrasound measurements after HTx.

\begin{tabular}{lll}
\hline Time since transplantation & Normal & Abnormal \\
\hline $\begin{array}{l}\text { Input examination } \\
\text { (one month after } \\
\text { transplantation) }\end{array}$ & MIT $0.25-0.5 \mathrm{~mm}$ & $\begin{array}{l}\text { Calcification, fibrotic plates and every intimal } \\
\text { lesion } \geq 0.5 \mathrm{~mm} \text { means } \\
\text { donor-transmitted atherosclerosis }\end{array}$ \\
$\begin{array}{l}\text { Control examination } \\
\text { (one year after }\end{array}$ & No changes in MIT & $\begin{array}{l}\text { Any change against initial } \\
\text { status }>0.5 \text { mm means }\end{array}$ \\
transplantation) & & $\begin{array}{l}\text { accelerated coronary } \\
\text { atherosclerosis }\end{array}$ \\
\hline
\end{tabular}


Table 2. Basic characteristics and breakdown of allograph recipients based on IVUS examination results one year after HTx.

\begin{tabular}{|c|c|c|c|c|c|}
\hline Parameter & Statistics & $\begin{array}{c}\text { DTA no } \\
\text { MIT }<0.5 \\
\mathrm{~N}=27 \\
\text { Group A }\end{array}$ & $\begin{array}{c}\text { DTA no } \\
\text { MIT }<0.5 \\
\mathrm{~N}=16 \\
\text { Group B }\end{array}$ & $\begin{array}{c}\text { DTA yes } \\
\mathrm{N}=8\end{array}$ & $P$-value \\
\hline Man & N (\%) & $22(81.5 \%)$ & $11(68.75 \%)$ & $7(87.5 \%)$ & 0.58 \\
\hline Woman & N (\%) & $5(18.5 \%)$ & $5(31.25 \%)$ & $1(12.5 \%)$ & \\
\hline \multirow[t]{3}{*}{ Age [years] } & Mean (SD) & 46.5 (13.7) & $47.8(9.7)$ & $43.5(14.5)$ & 0.76 \\
\hline & Median (Q1-Q3) & $50(38.5-58.5)$ & $49(41.75-55)$ & $40(31.75-60.25)$ & \\
\hline & Min - Max & $21-64$ & $30-62$ & $25-61$ & \\
\hline DM & N (\%) & $19(70.4 \%)$ & $7(43.8 \%)$ & $7(87.5 \%)$ & 0.09 \\
\hline HLPP & N (\%) & $20(74.1 \%)$ & $15(93.8 \%)$ & $6(75.0 \%)$ & 0.28 \\
\hline HT & N (\%) & $19(70.4 \%)$ & $12(75.0 \%)$ & $6(75.0 \%)$ & 1.00 \\
\hline
\end{tabular}

$\mathrm{DM}=$ diabetes mellitus HLPP = hyperlipidemia $\mathrm{HT}=$ hypertesnison

in both groups during the 1 year examination (Group A: MIT-M vs. MIT-Y, $0.26 \pm 0.09 \mathrm{~mm}$ vs. $0.35 \pm 0.15 \mathrm{~mm}$, P < 0.01; Group B: MIT-M vs. MIT-Y, $0.72 \pm 0.20 \mathrm{~mm}$ vs. $0.83 \pm 0.25 \mathrm{~mm}, P<0.01)$. In group $A$, the average did not exceed $0.5 \mathrm{~mm}$, unlike group $\mathrm{B}$, where the average exceeded $1 \mathrm{~mm}$ (Fig. 3).

\section{Lesion progression in the DTA Group}

In patients with DTA, the 1 year assessment showed no statistically significant changes in the vessel area (VA1M vs. VA1Y, $0.19 \pm 0.04 \mathrm{~mm}^{2}$ vs. $0.18 \pm 0.03 \mathrm{~mm}^{2}, P=0.15$; and VA2M vs. VA2Y, $0.13 \pm 0.02 \mathrm{~mm}^{2}$ vs. $0.12 \pm 0.03 \mathrm{~mm}^{2}, P=$ 0.44 , see Fig. 4. However, statistically significant narrowing of the vessel in the proximal section (LA1M vs. LA1Y, $0.13 \pm 0.04 \mathrm{~mm}^{2}$ vs. $0.10 \pm 0.01 \mathrm{~mm}^{2}, P=0.04$ and LA2M vs. LA2Y, $0.09 \pm 0.02 \mathrm{~mm}^{2}$ vs. $0.07 \pm 0.02 \mathrm{~mm}^{2}, P=0.052$, see Fig. 5) and statistically significant deterioration in the percent area stenosis in both vessel sections (PAS1M vsPAS1Y, $34.4 \pm 9.0 \%$ vs. $43.4 \pm 6.4 \%, P=0.01$ and PAS2M vs. PAS2Y, $32.3 \pm 6.9 \%$ vs. $44.6 \pm 6.2 \%, P=0.01)$ was revealed (Fig. 6).
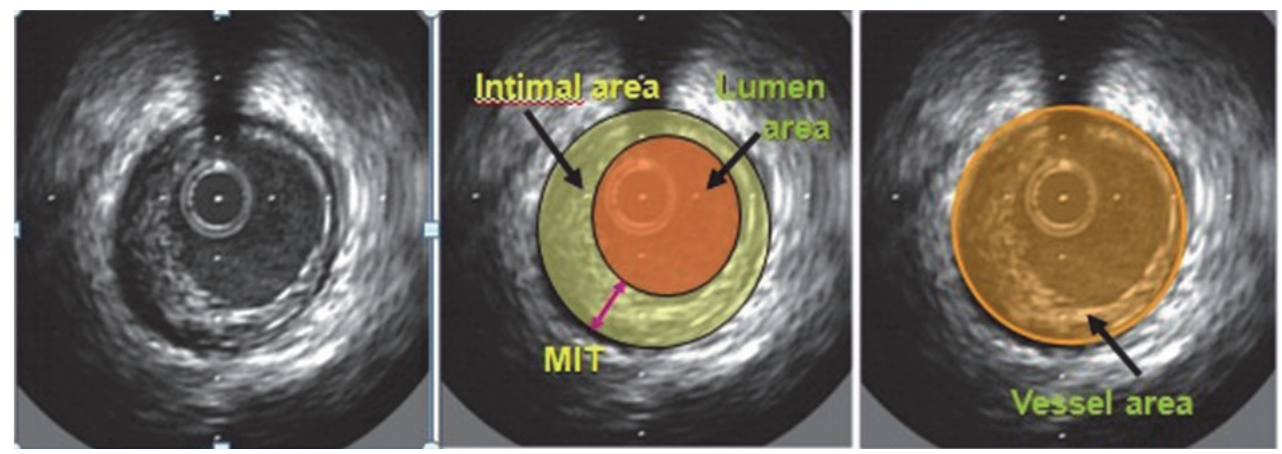

Fig. 1. Basic parameters of IVUS examination interpretation MIT $=$ maximal intimal thickness

Vessel area $=$ lumen area + intimal area

Percent area stenosis $=($ intimal area $/$ vessel area $) \times 100 \%$

\section{DISCUSSION}

In this study, we evaluated the relationship between the coronary artery wall parameters which were transmitted with the donor heart (assessed using IVUS) and the development of graft vasculopathy. The results showed a correlation between MIT value measured shortly after HTx and progression of CAV assessed during the 1 year follow up. In addition, we found a trend toward accelerated MIT progression in patients with MIT $\geq 0.5 \mathrm{~mm}$. These results are in an agreement with similar studies previously published ${ }^{8,11}$.

Today, CAV is among the most serious issues in heart transplantation. Challenges related to CAV start with diagnostics and continue with progression monitoring and therapy. There has been partial progress in all these aspects but this disease is still not satisfactorily under control which is dangerous for patients. CAV prevalence is highly variable. It can appear shortly after transplantation ( $<1$ year) and in such cases resembles an inflammatory vasculitis with a very bad prognosis ${ }^{5}$. If CAV appears later ( $>2$ years), it has a relatively slow progression and a relatively good prognosis. Fast-progressing or fulminant CAV, 


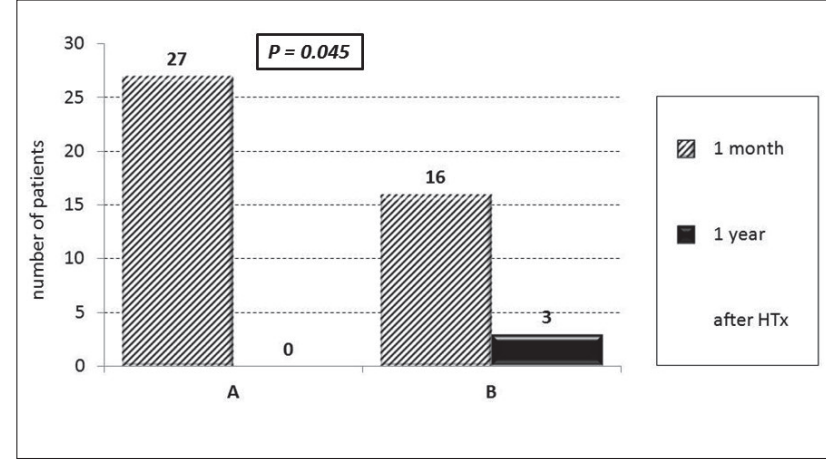

Fig. 2. Correlation between initial MIT and its progression over one year

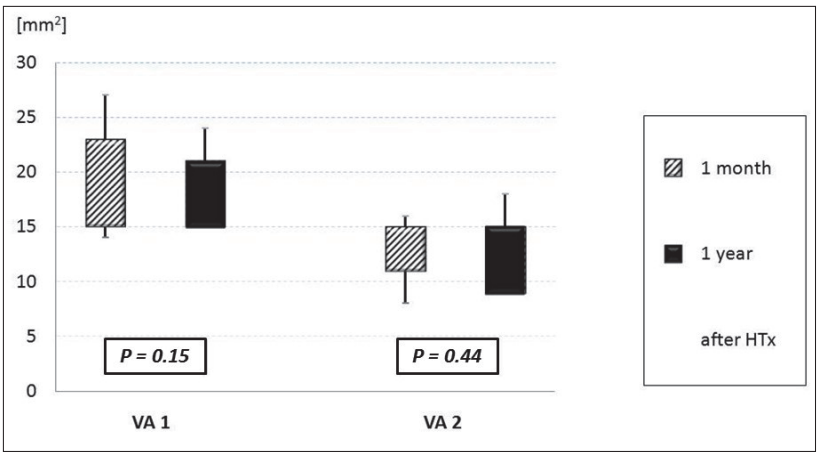

Fig. 4. DTA progression over one year $=\mathrm{VA} 1+\mathrm{VA} 2$ $\mathrm{VA}=$ vessel area

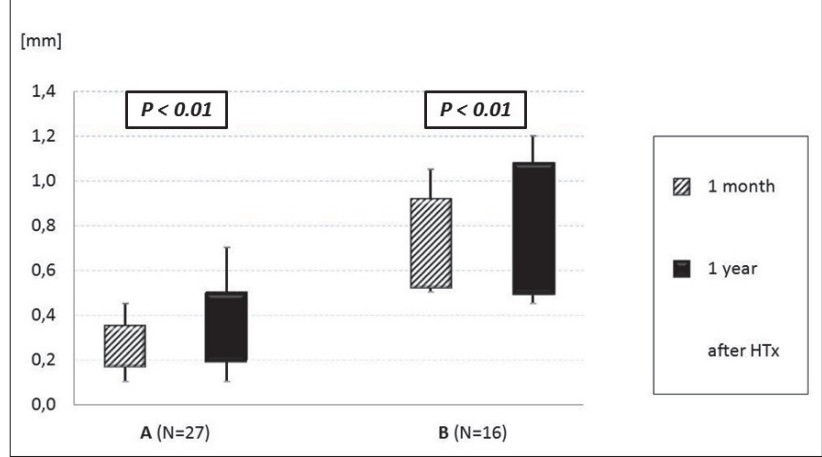

Fig. 3. MIT progression $<0.5 \mathrm{~mm}$ in one year $(\mathrm{n}=27)$ in group $\mathrm{A}$ and $\mathrm{B}$

MIT $=$ maximal intimal thickness

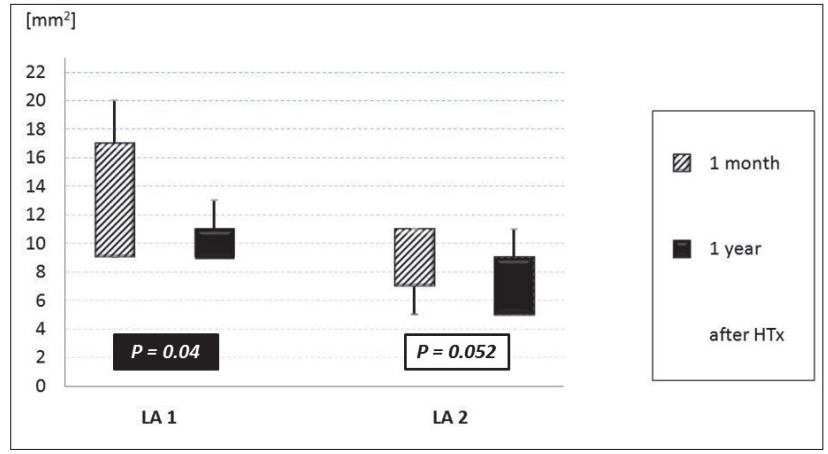

Fig. 5. DTA progression over one year $=\mathrm{LA} 1+\mathrm{LA} 2$

$\mathrm{LA}=$ lumen area

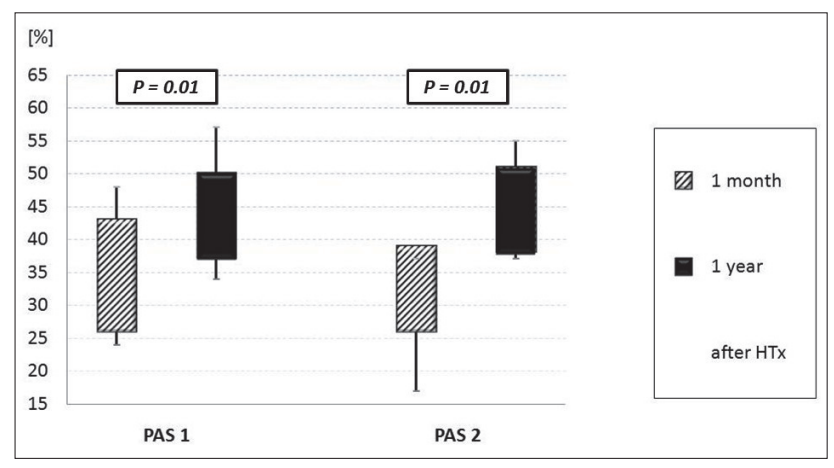

Fig. 6. DTA progression over one year $=$ PAS $1+$ PAS2

PAS $=$ percent area stenosis

defined as lesion $>70 \%$ within one year after baseline angiogram, has a very bad prognosis. The speed of CAV progression and the time of occurrence after transplantation are therefore the main risk factors for undesirable results after HTx (ref. ${ }^{12}$ ). It must be remembered, however, that the anatomic condition of CAV must be understood only as part of a syndrome in which the presence or absence of graft dysfunction as a result of CAV plays the key role and this dysfunction represents another strong predictive factor of impaired prognosis. Again, according to Gao, patients with CAV more than 2 years after transplantation and with LVEF $<40 \%$ have a significantly higher mortality rate after five years when compared to patients with CAV without left ventricle dysfunction or patients without CAV ( $60 \%$ vs. $90 \%$ vs. $92 \%, P<0.05)$. In this trial, mortality was evenly spread among patients with one, two or three vessels affected ${ }^{13}$.

Regarding the IVUS examination, number of studies showed that significant changes to intimal thickness, intimal area, intimal index and vessel area often occur already during the first year after HTx. Typically, the vessel area widens as a result of expansion when the intimal thickens, but the vessel lumen remains preserved. This explains why coronary angiography, the result of which is based on vessel lumen imaging, assesses the finding as normal but IVUS demonstrates significant CAV. Over the next 2-4 years, the so-called "constructive remodeling" arises in which the vessel area and vessel lumen are reduced ${ }^{14}$. 
These observations explain the enthusiasm for IVUS adoption in clinical trials investigating whether changes to $\mathrm{CAV}$, arising during the first year after transplantation, could be a predictor for subsequent significant CAV and thus the predictor for myocardial infarction, sudden death or the necessity of myocardium revascularization. Two large trials confirmed that a change to the maximum intimal thickness $\geq 0.5 \mathrm{~mm}$ in specific places of coronary branches which occurred during the first year after transplantation predicts worse results in five years after HTx with regard to mortality and myocardial infarction ${ }^{7,8}$.

Despite these relatively unambiguous results, there has been no consensus so far on how frequently the IVUS examination should take place.

The majority of centers routinely use coronary angiography in CAV diagnostics and IVUS is performed only where necessary. These techniques have their limitations, however, particularly poor spatial resolution and an insufficient qualitative and quantitative assessment of the coronary artery intima. This is the reason why optical coherence tomography (OCT) has been recently introduced, a new intracoronary imaging technique using optical ana$\log$ ultrasound with a space resolution of 10-20 $\mu \mathrm{m}, 10$ times more than what ultrasound allows ${ }^{15}$.

As already stated above, all patients were treated by immunosuppressive protocol consisting of a triple drug combination: cyclosporine A or tacrolimus, mycophenolate mofetil and steroids. In particular, steroid therapy may have contributed to the fact that two patients experienced pyrosis-like symptoms and dyspepsia, leading to the need of gastroscopy, which was, however, negative. During gastroscopy, as well as all other endoscopy examination, it is necessary to observe the principles of safe digestive endoscopy ${ }^{16-19}$.

Besides CAV diagnostics, IVUS is used for verifying new therapy strategies in patients after HTx. This mostly involves a modification of the immunosuppressive protocol in terms of the introduction of mTOR inhibitors. A number of studies showed a significant antiproliferation potential of this medication regarding CAV mitigation and deceleration and hence improved long-term mortality after HTx (ref. ${ }^{20-24}$ ).

Statins represent another medication which can positively influence CAV. Besides their effect on the reduction of blood fat levels, statins also have immunomodulative, cholesterol-independent effects, which is why they became a routine part of therapy protocols after HTx already upon publication of the Keogh trial ${ }^{25}$ in 1988. Statins in patients after HTx reduce the risk of sudden death and the prevalence of serious acute cellular rejections and prevent or at least decelerate CAV progression ${ }^{26,27}$.

Our trial has several limitations. First is the retrospective trial design. Second is a relatively small number of patients but this is an issue for all monocentric trials done on patients after HTx. This was also the reason for the relatively prolonged patient involvement in the trial. The last limitation of our trial is the lack of virtual histology as part of the IVUS examination, because we did not have this scheme available for all patients.

\section{CONCLUSION}

Our trial showed that CAV progresses significantly more frequently during the first year after HTx in patients with DTA and MIT $\geq 0.5 \mathrm{~mm}$. The IVUS control examination one year after transplantation is essential for these patients so that a change in treatment strategy and prevention or at least a deceleration of further disease progress can be achieved.

Acknowledgement: All authors were supported by a Grant IGA MZd CR NS 10627-3 and by European Regional Development Fund - Project FNUSA-ICRC No. CZ.1.05/1.1.00/02.0123.

Author contributions: HB: study design, data collection, manuscript writing; MO, PF, VH, MT, JK: data collection and analysis, PN: manuscript preparation, final approval. Conflict of interest statement: The authors state that there are no conflicts of interest regarding the publication of this article.

\section{REFERENCES}

1. Schmauss D, Weis M. Cardiac allograft vasculopathy: recent developments. Circulation 2008;117:2131-41.

2. Stehlik J, Edwards LB, Kucheryavaya AY, Benden C, Christie JD, Dobbels F, Kirk R, Rahmel AO, Hertz MI. The registry of the international society for heart and lung transplantation: Twenty-eighth adult heart transplant report--2011. J Heart Lung Transplant 2011;30:1078-94.

3. Starling RC. Advanced heart failure: Transplantation, LVADs, and beyond. Cleve Clin J Med 2013;80:33-40.

4. Hertz MI. The Registry of the International Society for Heart and Lung Transplantation--Introduction to the 2012 annual reports: new leadership, same vision J Heart Lung Transplant 2012;31(10):104551.

5. Hirohata A, Nakamura M, Waseda K, Honda Y, Lee DP, Vagelos RH, Hunt SA, Valantine HA, Yock PG, Fitzgerald PJ, Yeung AC, Fearon WF. Changes in coronary anatomy and physiology after heart transplantation. Am J Cardiol 2007;99:1603-7.

6. Weis M, von Scheidt W. Coronary artery disease in the transplanted heart. Annu Rev Med 2000;51:81-100.

7. Tuzcu EM, Kapadia SR, Sachar R, Ziada KM, Crowe TD, Feng J, Magyar WA, Hobbs RE, Starling RC, Young JB, McCarthy P, Nissen SE. Intravascular ultrasound evidence of angiographically silent progression in coronary atherosclerosis predicts long-term morbidity and mortality after cardiac transplantation. J Am Coll Cardiol 2005;45:1538-42.

8. Kobashigawa JA, Tobis JM, Starling RC, Tuzcu EM, Smith AL, Valantine HA, Yeung AC, Mehra MR, Anzai H, Oeser BT, Abeywickrama KH, Murphy J, Cretin N. Multicenter intravascular ultrasound validation study among heart transplant recipients: outcomes after five years. J Am Coll Cardiol 2005;45:1532-7.

9. Mehra MR, Crespo-Leiro MG, Dipchand A, Ensminger SM, Hiemann NE, Kobashigawa JA, Madsen J, Parameshwar J, Starling RC, Uber P. International society of heart lung transplantation workung formulation of a standardized nomenclature for cardiac allograft vasculopathy-2010. J Heart Lung Transplant 2010;29(7):717-27.

10. Mintz GS, Nissen SE, Anderson WD, Bailey SR, Erbel R, Fitzgerald PJ, Pinto FJ, Rosenfield K, Siegel RJ, Tuzcu EM, Yock PG. American College of Cardiology Clinical expert consensus document on standards for acquisition, measurement and reporting of intravascular ultrasound studies (IVUS). A report of the American College of Cardiology Task Force on Clinical Expert Consensus Documents. J Am Coll Cardiol 2001;37:1478-92

11. Yamasaki M, Sakurai R, Hirohita A, Honda Y, Bonneau HN, Luikart H, Yock PG, Fitzgerald PJ, Yeung AC, Valantine HA, Fearon WF. Impact of 
donor-transmitted atherosclerosis on early cardiac allograft vasculopathy: new findings by free-dimensional intravascular ultrasound analysis. Transplantation 2011;91(12):1406-11.

12. Kapadia SR, Nissen SE, Ziada KM, Guetta V, Crowe TD, Hobbs RE, Starling RC, Young JB, Tuzcu EM. Development of transplantation vasculopathy and progression of donor transmitted atherosclerosis: comparison by serial intravascular ultrasound paging. Cicrulation 1998;98(24):2672-8.

13. Gao SZ, Hunt SA, Schroeder JS, Alderman EL, Hill IR, Stinson EB. Early development of accelerated graft coronary artery disease: risk factors and course. J Am Coll Cardiol 1996;28:673-9.

14. Tsutsui $H$, Ziada KM, Schonhagen $P$, lyisoy A, Magyar WA, Crowe TD, Klingensmith JD, Vince DG, Rincon G, Hobbs RE, Yamagishi M, Nissen $\mathrm{SE}$, Tuzcu M. Lumen loss in transplant coronary artery disease is a biphasic process involving early intimal thickening and late constrictive remodeling: results from a 5-year serial intravascular ultrasound study. Circulation 2001;104:653-7.

15. Imamura T, Kinugawa K, Murasawa T, Kagami Y, Endo M, Muraoka H, Fujino T, Inaba T, Maki H, Hatano M, Kinoshita O, Nawata K, Kyo S, Komuro I, Ono M. Cardiac allograft vasculopathy can be distinguished from donor-transmitted coronary atherosclerosis by optical coherence tomography imaging in a heart transplantation recipient: double layered intimal thickness. Int Heart J 2014;55(2):178-80.

16. Kianicka B, Zak J, Bares M. The Use of Percutaneous Endoscopic Gastrostomy - Overview of Indications, Description of the Technique and Current Trends in Neurology. Cesk Slov Neurol 2012;75(2):165-9.

17. Kojecky V, Dolina J, Kianicka B, Misurec M, Varga M, Latta J, Vaculin V. A Single or Split Dose Picosulphate/Magnesium Citrate Before Colonoscopy: Comparison Regarding Tolerance and Efficacy with Polyethylene Glycol. A Randomized Trial. J Gastrointestin Liver Dis 2014;23(2):141-6.

18. Kianicka B, Lata J, Novotny I, Dite P, Vanicek J. Single balloon enteroscopy for endoscopic retrograde cholangiography in patients with Roux-en-Y hepatico-jejuno anastomosis. World J Gastroenterol 2013;19(44):8047-55.
19. Kianicka B, Dite P, Piskac P. Pitfalls of Pancreatobiliary Endoscopy after Billroth II Gastrectomy. Hepatogastroenterology 2012;59(113):17-21.

20. Raichlin E, Kushwaha SS. Proliferation signal inhibitors and cardiac allograft vasculopathy. Curr Opin Organ Transplant 2008;13(5):543-50.

21. Delgado JF, Manito N, Segovia J, Almenar L, Arizón JM, Campreciós M, Crespo-Leiro MG, Díaz B, González-Vílchez F, Mirabet S, Palomo J, Roig E, de la Torre JM. The use of proliferation signal inhibitors in the prevention and treatment of allograft vasculopathy in heart transplantation. Transplant Rev 2009;23(2):69-79.

22. Arora S, Ueland T, Wennerblom B, Sigurdadottir V, Eiskjær H, Bøtker HE, Ekmehag B, Jansson K, Mortensen SA, Saunamaki K, Simonsen S, Gude E, Bendz B, Solbu D, Aukrust P, Gullestad L. Effect of everolimus introduction on cardiac allograft vasculopathy - results of a randomized, multicenter trial. Transplantation 2011;92(2):235-43.

23. Chou NK, Jan CF, Chi NH, Lee CM, Wu IH, Huang SC, Chen YS, Yu HY, Tsao Cl, Ko WJ, Chu SH, Wang SS. Cardiac allograft vasculopathy compared by intravascular ultrasound sonography: everolimus to mycophenolate mofetil-one single-center experience. Transplant Proc 2012;44(4):897-9.

24. Matsuo Y, Cassar A, Yoshino S, Flammer AJ, Li J, Gulati R, Topilsky Y, Raichlin E, Lennon RJ, Lerman LO, Rihal CS, Kushwaha SS, Lerman A. Attenuation of cardiac allograft vasculopathy by sirolimus: Relationship to time interval after heart transplantation. J Heart Lung Transplant 2013;32:784-9.

25. Keogh A, Simons L, Spratt P, Esmore D, Chang V, Hickie J, Baron D. Hyperlipidemia after heart transplantation. J Heart Lung Transplant 1988;7:171-5.

26. Wu AH, Ballantyne CM, Short BC, Torre-Amione G, Young JB, Ventura HO, Eisen HJ, Radovancevic B, Rayburn BK, Lake KD, Yancy CW Jr, Taylor DO, Mehra MR, Kubo SH, Fishbein DP, Zhao XQ, O'Brien KD. Statin use and risks of death or fatal rejection in the Heart transplant lipid registry. Am J Cardiol 2005;95:367-72.

27. Wenke K, Meiser B, Thiery J, Nagel D, von Scheidt W, Steinbeck G, Seidel D, Reichart B. Simvastatin reduces graft vessel disease and mortality after heart transplantation. A four-year randomized trial. Circulation 1997;96:1398-402. 